\title{
An ongoing challenge and a chance to diversify university outreach to tackle inequality: A reply to O'Sullivan, O’Tuama and Kenny
}

\section{THIS IS A REPLY TO O’SULLIVAN, O’TUAMA AND KENNY}

Siobhan O’Sullivan, Seamus O'Tuama and Lorna Kenny (2017) explore aspects of inequality all too familiar within Higher Education and consider ways in which universities are key responders to educational inequality. I found the paper offered many points of connection with my own research in the past as well as current preoccupations. In this reply, I reflect on some past and present connections that relate to factors associated with engaging community groups and the notion of outreach.

\section{Context matters:}

The nature of our work reflects our working context, the wider policy influences but also our own educational and life stories. For instance, the writers' location within adult continuing education and their obvious commitment to community education and recognition of attendant intergenerational factors is evident. Like them, I believe engagement with community groups needs to be nuanced and responsive to the factors that contribute to inequality, which are not all the same for different communities. Due to their respective stages of development, the authors do not provide many details about their urban project, Cork Learning Neighbourhoods, or the pilot rural project, Skellig Centre for Research and Innovation, This was a pity as it deprived the article of the contextual current evidence to support the approach for which they were advocating. However, the rationale for their approach resonated with similar work by Lancaster's Community Access Programme (CAP) in the nineties (Preece and Houghton 2000). Based in contrasting communities, our work was located within East Lancashire, where we worked with mainly Muslim women, in Lancashire and Cumbria, where we worked with adults experiencing various physical and sensory impairments, unemployed men in Barrow and parents with no experience of higher education. Our action research enabled us to explore and tackle similar issues to those highlighted by the authors, both project teams engaging in community based education as part of our respective universities' commitments to regional lifelong learning.

A distinctive feature of the Community Access Programme (now known as REAP Researching Equity Access and Participation) and other projects delivered in English 
continuing education departments (for example, Leeds, Leicester, Nottingham, Sussex and Warwick) in the nineties was the development of culturally and socially relevant access courses. At Lancaster, we developed university-validated frameworks in consultation with the relevant community groups to provide relevant curricula to teach personal development, study, enterprise and basic research skills. We engaged in a mutually beneficial process of what we would describe today as co-creation. Our work reflected our commitment to tackling exclusion and promoting social justice and relied upon university community developer having the skills, cultural and social capital to work across specific community and university contexts.

Another point of continuity in the barriers some learners face is that of gaining access to information advice and guidance (IAG). Based on our research, we identified and explored IAG experiences and expectations of learners who were at, what we described as, a pre, preentry stage (Houghton and Oglesby, 1997). These learners often lacked the bridging social capital (Granovetter, 1983) that O'sullivan, O’Tuama and Kenny discuss in their paper. What is regrettable is that students from disadvantaged communities continue to believe that university is not for them. Sadly, this viewpoint, which was present in our work in the nineties, is something we continue to encounter in evaluation of current outreach activities working with younger people as well as their parents. Furthermore, it is a view expressed by some current undergraduate students who have overcome some of the attitudinal, social and economic barriers to apply and gain a place at university.

The intergenerational issues raised by O'Sullivan are ones that we explored in-depth during the era of Aimhigher as part of the Families And Higher Education FAHED project and Upto Uni a year-long intervention involving parents, teachers and young people and including community-based workshops, a summer residential and campus visit to a contrasting university. These action research projects emphasised the diversity of perspectives of families from different locale and highlighted how parental and wider family attitudes were influenced by previous educational experience as well as the local employment and economic contexts.

When reading O'Sullivan, O'Tuama and Kenny's paper, it was interesting to note the similarity of the adult education debates that have grown to accommodate those of lifelong learning, widening participation (WP) and, more recently, social mobility. Whilst the fundamental challenges seem to remain, the focus of attention changes with respect to the 
identity of the groups of learners that attract funders' attention and, therefore, become a priority. Yes, the funding initiatives colleagues in Cork and elsewhere are seeking to access and use to invest in activities to tackle inequality are different, but the challenges they outline are sadly familiar.

\section{Outreach for what purpose}

The second issue I wish to consider is the purpose and nature of outreach and how this does or does not support the suggestion that universities are key responders of education inequality. Although I agree with the authors' general points about factors that perpetuate patterns of participation, it is inevitable that the writers did not explore the complexity of the challenges facing universities as key responders to inequality. Recent research and evaluation undertaken by the Researching Equity, Access and Participation group at Lancaster have highlighted some of that complexity. For example, we have identified multiple motivations and responses by widening access students to different subject-focused summer schools. The benefits of adopting a collaborative approach to outreach is evidenced in work with the Dukes theatre as part of our Access Agreement, where the university has been able to engage with young women from the Gypsy Roma Travelling community to explore their views of education (see Youtube GRT: Our Voice The Dukes, 2016). Changes over time is another feature that adds to the complexity, something I explored when considering the changing issues associated with the transition of disabled students. The more recent evaluation of the transition experiences focused on a group of students on the autistic spectrum that barely participated ten years previously (Houghton, 2017). The outreach and induction activities of these students represent commitment to tackling inequality.

However, REAP's recent evaluation of outreach activities funded as part of our university Access Agreement coincided with a very different project, which also involved outreach, this time with the focus on inspiring the next generation of researchers. The RCUK-School University Partnership Initiative (RCUK-SUPI) project caused me and others to think about the use of the term outreach (For further details of this four-year project involving 12 universities funded by RCUK, 2017). Although SUPI also focused on outreach and had a remit of tackling inequality its purpose was to increase interest in and supporting progression into research. The emphasis was different and the extent to which this outreach represented a key response to education inequality varied. Over the lifetime of the project as the university began to consider sustainability one specific activity 'Research in a Box' gained additional access agreement funding designed to increase engagement with widening participation 
schools and learners. Some of these boxes also included research targeted at very relevant topics such as 'health inequalities' and 'rethinking disadvantage' (see Lancaster University 2017).

In our evaluation of widening access outreach and SUPI research outreach, we interacted with university staff and teachers in schools who were engaged in marketing and recruitment outreach. It appears that there are multiple groups of staff - community developers, widening participation practitioners, marketing and recruitment officers, admission tutors, undergraduate and postgraduate student ambassadors, early career researchers and, in our case, researchers involved in evaluation of the outreach activities. Since each group of staff engages in outreach for different reasons there is no guarantee that all activities will automatically tackle educational inequality advocated by the authors. The university is dependent on working in partnership and arguably it is the nature of those partnerships and the way university staff engaged in outreach that will determine whether, and to what extent, universities can be positioned as key responders to education inequality. In thinking about those partnerships, it seems important to consider what we each bring to the challenge of responding to education inequality, so that our work is complementary and not one of further competition, where some win and some lose.

\section{References}

Houghton, A and Oglesby, K L (1996) 'Guidance and Learner Support: Developing Threshold Standards', Adults Learning 7(6): 146-147

Houghton, A (1998) 'Extending the Guidance Boundaries: an exploration of educative and empowering guidance strategies for learners who have been long term unemployed', in J Preece, with, C Weatherald and M Woodrow (eds) Beyond the Boundaries: exploring the potential of widening provision in higher education, Leicester: NIACE.

Houghton, A. (2005) 'Who needs outreach to widen participation? Families or Higher Education' in Journal of Lifelong Learning and Widening Participation, 7(3): 5-15

Houghton, A. (2017) Getting through the gate is only the first hurdle: learning from disabled students and staff about their experience of inclusive teaching and learning. Adult Education for inclusion and diversity, SCUTREA 2017, University of Edinburgh. 
Lancaster University (2017) 'Research in a Box', Lancaster University Website [Online], http://www.lancaster.ac.uk/teachers/rcuk-schools-university-partnerships-initiative/researchin-a-box/ [Accessed 4 November 2017].

O’Sullivan, S., O’Tuama, S. and Kenny, L. (2017) ‘Universities as Key Responders to Educational Inequality', Global Discourse, 7:4

Preece, J. and Houghton, A. (2000) Nurturing Social Capital in Excluded Communities: A kind of Higher Education, Aldershot: Ashgate.

RCUK (2017) RCUK School-University Partnership project website [online] http://www.rcuk.ac.uk/pe/PartnershipsInitiative/ [Accessed 4 November 2017].

The Dukes (2016) GRT: Our Voice The Dukes, Lancaster University Access Agreement, available from: https://www.youtube.com/watch?v=X34G5OzOdl 